\title{
Functional outcomes in patients with chronic obstructive pulmonary disease: a multivariate analysis
}

\author{
Filipe T. S. Athayde ${ }^{1}$, Danielle S. R. Vieira ${ }^{2}$, Raquel R. Britto ${ }^{2}$, \\ Verônica F. Parreira ${ }^{2}$
}

\begin{abstract}
Background: Multiple factors can influence the severity of chronic obstructive pulmonary disease (COPD) and the functioning of patients with COPD, such as personal characteristics and systemic manifestations. Objective: To evaluate the different factors that can influence the activity and psychosocial impact domains of the Saint George's Respiratory Questionnaire (SGRQ) in COPD patients. Method: Participants, recruited in a university-based hospital, responded to the SGRQ, and in addition, personal, anthropometric, and clinical data were collected. The study was approved by the Institutional Ethics Committee. Data were analyzed using multiple linear regression models, with the SGRQ activity and psychosocial impact scores as outcome variables, and 10 explanatory variables (age, gender, forced expiratory volume in the first second - $\mathrm{FEV}_{1}$, smoking load, body mass index, oxygen therapy, associated diseases, regular physical activity, participation in a formal rehabilitation program, and SGRQ symptoms score) were considered. Results: The best regression model for predicting the SGRQ activity score $\left(r^{2}=0.477\right)$ included gender, FEV ${ }_{1}$, and SGRQ symptoms. In contrast, the predictive model with the highest proportion of explained variance in psychosocial impact score $\left(r^{2}=0.426\right)$ included the variables gender, oxygen therapy, and SGRQ symptoms. Conclusions: The results indicate that the outcomes, while based on functioning parameters in COPD patients, could be partly explained by the personal and clinical factors analyzed, especially by the symptoms assessed by the SGRQ. Thus, it appears that the health conditions of these patients cannot be described by isolated variables, including pulmonary function parameters.
\end{abstract}

Keywords: chronic obstructive pulmonary disease; health status; disability evaluation; physical activity; physical therapy; rehabilitation.

\section{HOW TO CITE THIS ARTICLE}

Athayde FTS, Vieira DSR, Britto RR, Parreira VF. Functional outcomes in patients with chronic obstructive pulmonary disease: a multivariate analysis. Braz J Phys Ther. 2014 Jan-Feb; 18(1):63-71. http://dx.doi.org/10.1590/S1413-35552012005000142

\section{Introduction}

Chronic obstructive pulmonary disease (COPD) can affect various aspects of patients' lives, including their ability to perform daily activities. The progressive worsening of symptoms, particularly of dyspnea, is associated with negative impacts on patients' professional, social, and family lives, thus significantly impairing their quality of life $\mathrm{e}^{1-4}$. As recognized by the Global Initiative for Chronic Obstructive Lung Disease (GOLD), the impact of COPD on an individual depends not only on the degree of airflow limitation, which can be measured by the forced expiratory volume in the first second $\left(\mathrm{FEV}_{1}\right)$, but also on the severity of symptoms, the systemic effects of the disease, and associated comorbidities ${ }^{5}$.

With the implementation of the International Classification of Functioning, Disability and Health (ICF) ${ }^{6}$, developed by the World Health Organization, it has become possible to describe the typical spectrum of function in patients with $\mathrm{COPD}^{7}$. The ICF model is based on a biopsychosocial approach in which functioning and disability are considered to be a dynamic interaction between health conditions and contextual factors. The term 'functioning' in the ICF refers to all three dimensions taken together (Body Functions and Body Structures, Activities, and Participation $^{8,9}$.

According to the Statement on Pulmonary Rehabilitation, published by the American Thoracic Society and the European Respiratory Society, the isolated evaluation of only $\mathrm{FEV}_{1}$ does not represent the complex clinical consequences of $\mathrm{COPD}^{10}$. Recently, a study was published showing earlier mortality and worse health-related quality of life (HRQOL) in patients with severe or very severe COPD $^{11}$. However, several authors have debated

\footnotetext{
${ }^{1}$ Graduate Program in Rehabilitation Sciences, Universidade Federal de Minas Gerais (UFMG), Belo Horizonte, MG, Brazil 
and considered inadequate the use of $\mathrm{FEV}_{1}$ as the unique parameter for evaluating and categorizing patients with COPD ${ }^{4,12-16}$. Airflow obstruction is only one of the various components of the disease, which usually progresses with other pathophysiological aspects, such as hyperinflation, decreased exercise capacity, malnourishment, and reduced muscle strength, among others ${ }^{15}$. In the complex mechanism of COPD development, systemic manifestations are as important as pulmonary function parameters ${ }^{16}$.

Currently, the recognized importance of systematic assessment of the symptoms and functional limitations associated with COPD, to optimize interventions and quantify gains, has resulted in the development and use of various specific instruments of measurement, designed to be used in this health condition? Stucki et al. ${ }^{17}$ compared the content of instruments used to assess HRQOL in patients with COPD, using the ICF as reference. They demonstrated that, among the eleven instruments included in the study, there was great diversity in the ICF components covered, and the Saint George's Respiratory Questionnaire (SGRQ) was the instrument that incorporated the highest number of these.

Considering the function and disability model proposed by the ICF and the most recent literature in this area, the isolated use of $\mathrm{FEV}_{1}$ seems to be insufficient to characterize COPD patients. In addition to pulmonary function parameters that identify the primary disorder of the disease, other aspects that influence the health status of this patient population should also be considered. Among these aspects, we emphasize personal characteristics, the presence of comorbidities, systemic manifestations, the level of physical activity, participation in formal pulmonary rehabilitation programs and the need for supplemental oxygen, as well as social and family support. Thus, the aim of this study was to evaluate the different factors that can influence functional outcomes in patients with COPD. The activity and psychosocial impact domains of the SGRQ were considered as functional outcomes.

\section{Method}

\section{Sample}

This was an observational, cross-sectional study, conducted at a university-based hospital. The following inclusion criteria were considered: diagnosis of COPD confirmed by recent pulmonary function testing, considering the GOLD criteria with negative bronchodilator response, defined as an increase in $\mathrm{FEV}_{1}$ of less than $12 \%$; no other obstructive respiratory diseases and an associated absence of a clinical history suggestive of asthma; regular clinical monitoring (at least on a quarterly basis); and clinical stability of at least three months (without hospitalization or exacerbation) ${ }^{18}$. The presence of cognitive impairment, as assessed by the Mini-Mental State Examination, was considered an exclusion criterion $^{19}$. This study was approved by the Ethics Committee of Universidade Federal de Minas Gerais (UFMG), Belo Horizonte, MG, Brazil (ETIC No. 424/08); and all participants signed an informed consent form.

\section{Measurement instrument}

The SGRQ is a standardized instrument that assesses perceived HRQOL in patients with respiratory disease ${ }^{20,21}$. It consists of three independent domains: symptoms, activity, and psychosocial impact. These areas cover, respectively, the frequency and severity of respiratory symptoms, activities that cause or are limited by dyspnea, and aspects related to social functioning and psychological disorders due to the disease ${ }^{21}$.

Originally developed by Jones et al..$^{21}$, the SGRQ was translated, adapted, and validated for the Brazilian population by De Sousa et al. ${ }^{22}$ and Camelier et al. ${ }^{20}$. The latter version was used in this study. Specific software provided four final scores: a total score and three scores for each of the three domains ${ }^{21}$. Each score ranged from zero to 100 , with higher values representing worse health conditions $^{20-22}$.

\section{Procedures}

Anthropometric and clinical data and spirometry results registered in hospital records were collected at the initial evaluation. Then, the SGRQ was applied via interviews conducted by a single researcher who had been previously trained.

Eight patients were selected for investigation of intra-examiner reliability in the application of the SGRQ. These patients were asked to respond to the questionnaire a second time after a period of one week, at the same location and time as the first assessment. By means of the intraclass correlation coefficient, using the consistency model $(3,1)^{23}$, the reliability of the measurement was $0.98,0.96$, 0.89 , and 0.96 for the total score and the sub-scores of symptoms, activity, and psychosocial impact, respectively.

\section{Variables analyzed}

The dependent variables explained by the model were the SGRQ activity and psychosocial impact scores. The independent or explanatory variables 
were the personal, anthropometric, and clinical characteristics of the COPD patients, including the SGRQ symptoms score.

Among the explanatory variables, ten factors were used to construct the analytical model of multiple regression: age, gender, body mass index, smoking load, $\mathrm{FEV}_{1}$, regular physical activity, participation in a formal rehabilitation program, associated diseases, oxygen therapy, and the SGRQ symptoms score.

Body mass index (BMI), in $\mathrm{kg} / \mathrm{m}^{2}$, was calculated using the following formula: BMI = weight/ height $^{2}$ (Filizola Ind. Ltda., São Paulo, SP, Brazil). Smoking load, in pack-years, was quantified by the mathematical product of duration of smoking habit and number of packs of cigarettes smoked daily ${ }^{24,25}$.

$\mathrm{FEV}_{1}$, obtained by the pulmonary function test, represents the volume of air exhaled in one second of the FVC maneuver, expressed in liters and as a percentage of predicted value ${ }^{26}$. This parameter reflects the degree of airway obstruction and classifies patients into four stages of disease severity ${ }^{5}$.

The variable "regular physical activity" distinguished patients who exercised regularly from those who were sedentary. Regular physical activity was considered moderate intensity exercise (three to six METs) for at least 30 minutes on most days of the week ${ }^{27}$. With regard to participation in formal physical rehabilitation programs ${ }^{10,28}$, patients who engaged in or had previously engaged in these programs were distinguished from those who had never attended this type of intervention.

Diseases associated with COPD and other non-obstructive respiratory diseases, as well as cardiovascular, neurological, metabolic, rheumatologic, orthopedic, and other disorders, were operationalized in a qualitative and dichotomized form, identifying the presence or absence of comorbidities by patients' self-report. Oxygen therapy was characterized regarding the routine use or absence of supplemental oxygen, regardless of the form or quantity offered.

The SGRQ symptoms score was included in the predictive model, characterizing the patients' perceptions regarding the intensity and frequency of respiratory symptoms. This score does not show an interrelationship with the other scores of the questionnaire, i.e. there is no overlap of the items that are evaluated by the instrument ${ }^{20,29}$.

\section{Data analysis}

Descriptive statistics were used to characterize the patients. Multiple linear regression models, by the enter and stepwise methods, were constructed to examine the associations between the dependent and independent variables. First, the KolmogorovSmirnov normality test and Spearman's linear correlation were used for the data analysis. All of the assumptions of the statistical method were respected, including the absence of multicollinearity among the 10 independent variables ${ }^{23}$.

A sample calculation was initially performed according to the following formula: $(10 *[\mathrm{k}+1])$, where $\mathrm{k}$ represents the number of explanatory variables of the predictive model ${ }^{30}$. Thus, considering the 10 independent variables as contributing to explaining the predictive model, the number of research participants should have initially been 110 . After analyzing the data from the first 72 patients, four independent variables, at the most, were included in the predictive model, and therefore, a minimum of 50 patients would be necessary for the analysis. The SPSS statistical package (SPSS version 17.0, Chicago, IL, USA) was used for the data analysis.

\section{Results}

Of the 88 eligible patients with COPD, 73 met the inclusion criteria and were evaluated. One patient was excluded due to cognitive impairment. Thus, 72 volunteers participated in the study. The patients had a mean age of $65.86 \pm 9.25$ years; 47 of them $(65.3 \%)$ were male, and 34 (47.2\%) were classified as GOLD III stage. Table 1 summarizes the characteristics of the sample. With regard to clinical conditions associated with COPD, there was a great diversity of diseases identified, with emphasis on arterial hypertension in 50 patients $(69.44 \%)$, dyslipidemia in $26(36.11 \%)$, diabetes mellitus in nine $(12.5 \%)$, history of pulmonary tuberculosis in eight $(11.11 \%)$, and depression in seven (9.72\%). Regarding smoking, six participants $(8.33 \%)$ had never smoked, and seven $(9.72 \%)$ were still active smokers. The mean duration of the pulmonary function tests was $3.31 \pm 2.16$ months (without exacerbations in this period).

Table 2 presents the results of the correlation analysis between the explained and explanatory variables of the regression. A significant linear correlation (Spearman) was found between the SGRQ activity and psychosocial impact scores and the following variables: gender, $\mathrm{FEV}_{1}$, oxygen therapy, and SGRQ symptoms score. Through regression analysis using the enter method, which included the four independent variables that were significantly correlated with the outcome variables, adjusted determination coefficients $\left(\mathrm{r}^{2}\right)$ of 0.498 (activity) and 0.417 (psychosocial impact) were obtained. 
Table 1. General characteristics of all COPD patients.

\begin{tabular}{cc} 
Variables & Patients $(\mathbf{n}=\mathbf{7 2})$ \\
Age (years) & $65.86 \pm 9.25(42-88)$ \\
Gender (male/female) & $47(65.3 \%) / 25(34.7 \%)$ \\
Body mass index (kg/m2) & $25.1 \pm 5.13(15.44-45.96)$ \\
Smoking load (pack-years) & $44.96 \pm 29.99(0-120)$ \\
FEV1 (\% predicted) & $48.54 \pm 21.54(17-105)$ \\
GOLD stage I (mild) & $7(9.7 \%)$ \\
GOLD stage II (moderate) & $18(25 \%)$ \\
GOLD stage III (severe) & $34(47.2 \%)$ \\
GOLD stage IV (very severe) & $13(18.1 \%)$ \\
physical activity (active/sedentary) & $21(29.2 \%) / 51(70.8 \%)$ \\
gram (participates or has participated/never participated) & $11(15.3 \%) / 61(84.7 \%)$ \\
SGRQ Total score & $66(91.7 \%) / 6(8.3 \%)$ \\
SGRQ Symptoms score & $10(13.9 \%) / 62(86.1 \%)$ \\
SGRQ Activity score & $42.99 \pm 17.89(8.19-77.93)$ \\
GRQ Psychosocial impact score & $50.51 \pm 22.21(5.94-93.19)$ \\
\hline
\end{tabular}

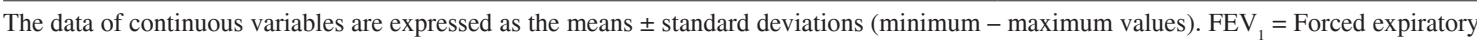
volume in the first second; GOLD = Global Initiative for Chronic Obstructive Lung Disease, SGRQ = Saint George Respiratory Questionnaire . The data of categorical variables (gender, COPD stage, regular physical activity, formal rehabilitation program, associated diseases, and oxygen therapy) are expressed as numbers of patients in each class (percentage of the overall sample).

Table 2. Linear correlation (r) between SGRQ activity and psychosocial impact scores and the explanatory variables of regression analysis.

\section{Explanatory variables}

Age

Gender

BMI

Smoking load

$\mathrm{FEV}_{1}$

Regular physical activity

Formal rehabilitation program

Associated diseases

Oxygen therapy

SGRQ Symptoms
SGRQ Activity

$\mathbf{r}$

0.009

0.329

0.041

0.056

$-\mathbf{0 . 4 3 3}$

0.032

0.046

0.129

0.294

0.611
SGRQ Psychosocial impact

p

0.937

0.005*

0.733

0.642

0.000*

0.787

0.704

0.279

0.012*

$0.000 *$ r

$-0.134$

0.366

0.064

0.095

$-0.308$

0.062

0.069

0.005

0.354

$\mathbf{0 . 5 2 7}$ p

0.261

0.002*

0.591

0.428

0.009*

0.606

0.566

0.968

0.002*

0.000*

$\mathrm{BMI}=$ Body mass index; $\mathrm{FEV}_{1}=$ Forced expiratory volume in the first second; SGRQ=Saint George Respiratory Questionnaire. * $\mathrm{p}<0.05$, obtained using Spearman correlation, indicating the explanatory variable that was incorporated into the regression model.

Table 3 shows the three regression models obtained by the stepwise method for the two study outcomes (activity and psychosocial impact scores).

With regard to activity, three explanatory variables (gender, FEV ${ }_{1}$ and SGRQ symptoms score) were included in the final model. The proportion of the variance explained by the model that included only the symptoms score as an explanatory variable was $36.5 \%$, while the model that included these three variables had a proportion of variance of $47.7 \%$. The latter regression model (model 3 ) is described by the equation below (Equation 1):

SGRQ Activity $=41.101+(0.496 \times$ SGRQ symptoms $)-$ $-(0.242 \times$ FEV $1 \%$ predicted $)+(9.763 \times$ gender $)$ 
Table 3. Linear regression models by stepwise method to predict SGRQ activity and psychosocial impact scores.

\begin{tabular}{ccc}
\hline & SGRQ Activity Score & \\
Predictive Models & Explanatory Variables & $\mathbf{r}^{2}$ Adjusted \\
Model 1 & SGRQ symptoms & 0.365 \\
Model 2 & SGRQ symptoms and FEV & 0.436 \\
Model 3 & SGRQ symptoms, FEV ${ }_{1}$ and gender & 0.477 \\
& SGRQ Psychosocial Impact Score & $\mathbf{r}^{2}$ Adjusted \\
Predictive Models & Explanatory Variables & 0.270 \\
Model 1 & SGRQ symptoms & 0.360 \\
Model 2 & SGRQ symptoms and oxygen therapy & 0.426 \\
\hline
\end{tabular}

SGRQ=Saint George Respiratory Questionnaire; FEV $=$ =Forced expiratory volume in the first second.

The variable "gender" was assigned a "0" for men and a "1" for women.

With regard to psychosocial impact, the following explanatory variables were included in the final model: gender, oxygen therapy, and SGRQ symptoms score. The proportion of the variance explained by the model that included only the symptoms score was $27 \%$, while the model that included the three variables yielded a proportion of the variance of $42.6 \%$. The latter regression model is described by the equation below (Equation 2):

SGRQ psychosocial impact $=6.561+$

$+(0.389 \times$ SGRQ symptoms $)+$

$+(16.849 \times$ oxygen therapy $)+(10.771 \times$ gender $)$

The variable "oxygen therapy" was assigned the rating " 0 " for patients who did not use supplemental oxygen and " 1 " for patients who used oxygen; for "gender", "0" was assigned for men and "1" for women.

\section{Discussion}

The present study aimed to identify the factors that influence the functioning of patients with COPD, operationalized by the SGRQ activity and psychosocial impact scores. For the activity score, the best regression model obtained $\left(r^{2}=0.477\right)$ included the SGRQ symptoms score, $\mathrm{FEV}_{1}$, and gender. The greatest contribution to the total variance $(36.5 \%)$ in the comparative analysis of the three models generated by the stepwise method was from the SGRQ symptoms score. Regarding the psychosocial impact score, the greatest contribution was also from the symptoms score, in addition to gender, and oxygen therapy. With regard to this latter outcome, $\mathrm{FEV}_{1}$ was not included in the final model.
The SGRQ activity score reflects the activities that cause or are limited by dyspnea ${ }^{21}$, and it seems to be an appropriate way to operationalize activity limitations, according to the ICF, in patients with $\mathrm{COPD}^{17}$. Different studies have shown that other variables, in addition to the factors investigated in this study, were correlated with the SGRQ activity score, such as physical activity level (measured in accelerometers) during activities of daily living ${ }^{2,31,32}$, and exercise capacity (including the six-minute walk test [6MWT], cardiopulmonary exercise testing and specific questionnaires) $)^{33-37}$.

Regarding variables derived from physical activity, Pitta et al. ${ }^{38}$ observed low-magnitude, nonsignificant associations with $\mathrm{FEV}_{1}$. With regard to exercise capacity, low to moderate correlations ${ }^{39}$ or an absence of a significant association with $\mathrm{FEV}_{1}{ }^{14,38}$ was found. Foglio et al. ${ }^{40}$ observed that 26 to $34 \%$ of the exercise capacity variance in patients with airflow obstruction was explained by age, dyspnea, and pulmonary hyperinflation. $\mathrm{FEV}_{1}$ was not included in this predictive model. Wijkstra et al. ${ }^{41}$ evaluated 40 patients with COPD and showed significant contributions of the variables carbon monoxide diffusing capacity (DLCO) and maximal inspiratory pressure (MIP) to explaining the variance in the distance walked in the 6MWT $\left(r^{2}=0.61\right)$ and the maximal workload reached in the cycle ergometer test $\left(r^{2}=0.54\right)$, without the significant participation of $\mathrm{FEV}_{1}$.

The results of the present study corroborate in a way the results observed in previous studies, reiterating the small importance of degree of airway obstruction with regard to activity in patients with COPD. In addition, our results reinforce the relevance of symptoms, especially dyspnea, and the 
differences between the genders in understanding this phenomenon.

The SGRQ psychosocial impact score indicates the aspects related to social and psychological disorders secondary to the disease ${ }^{21}$. Some studies have investigated outcomes related to the psychosocial impact of COPD ${ }^{11,15,39,42-45}$. In the present study, the linear regression models to explain this variable did not identify $\mathrm{FEV}_{1}$ as a significant contributing factor, which corroborates the results of Huijsmans et al. ${ }^{39}$. These authors did not observe significant difference in the SGRQ psychosocial impact score when comparing patients with GOLD stages II, III, and IV. The correlation between this score and FEV was weak although statistically significant $(\mathrm{r}=-0.19$, $\mathrm{p}=0.02$ ). Similarly, Araujo and Holanda ${ }^{11}$ did not detect a significant difference between the SGRQ psychosocial impact scores of two groups of COPD patients with $\mathrm{FEV}_{1} \geq 50 \%$ predicted and $\mathrm{FEV}_{1}<50 \%$ predicted. The study of Verhage et al. ${ }^{15}$ found no significant correlation between $\mathrm{FEV}_{1}$ and a variable designated "satisfaction in social relationships", and they did not find any significant differences between patients with GOLD stages II and III with regard to this factor.

Regarding the differences related to gender, the women presented worse scores for the activity and psychosocial impact domains. Similar results have been reported in the literature. Ferrari et al. ${ }^{43}$ reported significant differences in the psychosocial impact scores between men and women, with worse scores for women, while De Torres et al. ${ }^{42}$ showed significant differences between the genders in the SGRQ activity score.

With regard to oxygen therapy, an observational study did not find a significant reduction in the SGRQ scores of COPD patients who used longterm supplemental oxygen, although a decrease was observed in the physical and social function scores in the SF-36 questionnaire. The authors found a greater correlation between the SGRQ psychosocial impact score and the dyspnea level of the patients $(r=0.73$, $\mathrm{p}<0.001)^{44}$. Our results corroborate those reported by Tanni et al. ${ }^{45}$, who observed a significantly worse SGRQ psychosocial impact score in COPD patients with chronic hypoxemia who had undergone prolonged oxygen therapy. These authors also found a weak correlation between this score and $\mathrm{FEV}_{1}(\mathrm{r}=-0.37, \mathrm{p}<0.05)$. When stratifying COPD severity by degree of dyspnea (using the MRC scale), Garrod et al. ${ }^{35}$ observed a significant difference in the SGRQ total scores between groups, without reporting the scores for each domain.
As limitations of this study, the simplified dichotomous operationalization of the following explanatory variables should be noted: associated diseases, oxygen therapy, formal rehabilitation program and regular physical activity, as well as the absence of other relevant measured factors in research and routine clinical practice, such as the MRC dyspnea scale.

The variables most widely studied to understand the mechanisms involved in COPD remain mostly components of body structure and function in the ICF model ${ }^{46-51}$. Thus, it is very important to encourage the development of future studies that address the domains of activities and social participation and the environmental factors of the ICF. Moreover, there have been a relatively small number of studies on factors related to the psychological and social impact of COPD. Therefore, the findings of the present study could contribute to increasing the body of evidence in this area.

This study enabled the identification of variables in common use in our clinical practice to predict functioning parameters. The evaluation of the participants in a clinical outpatient setting may reflect more appropriately the functional profile of COPD patients attending health services. In rehabilitation practice, the patient's symptoms are the main guide for proposed interventions, an important finding of this study in relation to the determination of functional outcomes. Furthermore, other factors identified in the present study could help therapists to develop a more comprehensive evaluation and provide more adequate assistance for the patients along their disease progression.

\section{Conclusions}

Our results showed that the functional outcomes studied were partially explained by personal and clinical factors. Additionally, it was possible to emphasize the insufficiency of the parameter of lung function $\left(\mathrm{FEV}_{1}\right)$ in explaining the complex phenomenon of functioning in patients with COPD.

Among the factors identified in the regression analysis that influenced the functional outcomes investigated, three variables were observed that were non-modifiable (gender) or that were unlikely to be changed by interventions ( $\mathrm{FEV}_{1}$ and oxygen therapy). However, the variable with the greatest contribution to the analyzed outcomes was the symptoms score, which should be the main guideline and focus when clinically managing these patients. 


\section{Acknowledgements}

This work was supported by the Pró-Reitoria de Pesquisa da Universidade Federal de Minas Gerais, as well as Conselho Nacional de Desenvolvimento Científico e Tecnológico (CNPq), Brasilia, DF, Brazil (Grant 306722/2010-0) and Fundação de Amparo à Pesquisa do Estado de Minas Gerais (FAPEMIG), Belo Horizonte, MG, Brazil (PPM-00374-12). These research grant agencies had no influence in the study design; in the collection, analysis, and interpretation of data; in the writing of the report; or in the decision to submit the paper for publication.

\section{References}

1. Velloso M, Jardim JR. Functionality of patients with chronic obstructive pulmonary disease: energy conservation techniques. J Bras Pneumol. 2006;32(6):5806. http://dx.doi.org/10.1590/S1806-37132006000600017

2. Steele BG, Belza B, Cain K, Coppersmith J, Howard $\mathrm{J}$, Lakshminarayan $\mathrm{S}$, et al. The impact of chronic obstructive pulmonary disease exacerbation on pulmonary rehabilitation participation and functional outcomes. J Cardiopulm Rehabil Prev. 2010;30(1):53-60. http://dx.doi. org/10.1097/HCR.0b013e3181c85845

3. Rodriguez Gonzalez-Moro JM, De Lucas RP, Izquierdo Alonso JL, Lopez-Muniz BB, Anton DE, Ribera X, et al. Impact of COPD severity on physical disability and daily living activities: EDIP-EPOC I and EDIP-EPOC II studies. Int J Clin Pract. 2009;63(5):742-50. http://dx.doi. org/10.1111/j.1742-1241.2009.02040.x

4. Aguilaniu B, Gonzalez-Bermejo J, Regnault A, Barbosa CD, Arnould B, Mueser M, et al. Disability related to COPD tool (DIRECT): towards an assessment of COPD-related disability in routine practice. Int J Chron Obstruct Pulmon Dis. 2011;6:387-98. PMid:21760726 PMCid:PMC3133511. http://dx.doi.org/10.2147/COPD. S20007

5. Global Initiative for Chronic Obstructive Pulmonary Disease. Global Strategy for the diagnosis, management, and prevention of chronic obstructive pulmonary disease. GOLD [Internet]. 2011 [cited 2012 Sep 10]. Available from: http://www.goldcopd org.

6. World Health Organization - WHO. International classification of functioning, disability and health: ICF. WHO; 2001.

7. Stucki A, Stoll T, Cieza A, Weigl M, Giardini A, Wever D, et al. ICF Core Sets for obstructive pulmonary diseases. J Rehabil Med. 2004;44(Suppl):114-20. http://dx.doi. org/10.1080/16501960410016794

8. Jette AM. Toward a common language for function, disability, and health. Phys Ther. 2006;86(5):726-34. PMid:16649895.

9. Sampaio RF, Luz MT. Human functioning and disability: exploring the scope of the World Health Organization's international classification. Cad Saude
Publica. 2009;25(3):475-83. http://dx.doi.org/10.1590/ S0102-311X2009000300002

10. Nici L, Donner C, Wouters E, ZuWallack R, Ambrosino N, Bourbeau J, et al. American Thoracic Society/European Respiratory Society statement on pulmonary rehabilitation. Am J Respir Crit Care Med. 2006;173(12):1390-413. http://dx.doi.org/10.1164/rccm.200508-1211ST

11. Araujo ZT, Holanda G. Does the BODE index correlate with quality of life in patients with COPD? J Bras Pneumol. 2010;36(4):447-52. http://dx.doi.org/10.1590/ S1806-37132010000400009

12. Ferrari R, Tanni SE, Faganello MM, Caram LMO, Lucheta PA, Godoy I. Three-year follow-up study of respiratory and systemic manifestations of chronic obstructive pulmonary disease. Braz J Med Biol Res. 2011;44(1):46-52. http:// dx.doi.org/10.1590/S0100-879X2010007500150

13. Nishimura K, Izumi T, Tsukino M, Oga T. Dyspnea is a better predictor of 5-year survival than airway obstruction in patients with COPD. Chest. 2002;121(5):1434-40. http://dx.doi.org/10.1378/chest.121.5.1434

14. Silva KR, Marrara KT, Marino DM, Di Lorenzo VAP, Jamami M. Skeletal muscle weakness and exercise intolerance in patients with chronic obstructive pulmonary disease. Rev Bras Fisioter. 2008;12(3):169-75. http:// dx.doi.org/10.1590/S1413-35552008000300003

15. Verhage TL, Heijdra YF, Molema J, Daudey L, Dekhuijzen PN, Vercoulen JH. Adequate Patient Characterization in COPD: Reasons to Go Beyond GOLD Classification. Open Respir Med J. 2009;3:1-9. http://dx.doi. org/10.2174/1874306400903010001

16. Yorgancioglu A, Havlucu Y, Celik P, Dinc G, Saka A. Relation between quality of life and morbidity and mortality in COPD patients: Two-year follow-up study. COPD. 2010;7(4):248-53. http://dx.doi.org/10.3109/154 12555.2010.496816

17. Stucki A, Stucki G, Cieza A, Schuurmans MM, Kostanjsek $\mathrm{N}$, Ruof J. Content comparison of health-related quality of life instruments for COPD. Respir Med. 2007;101(6):1113 22. http://dx.doi.org/10.1016/j.rmed.2006.11.016

18. Takabatake N, Nakamura H, Abe S, Inoue S, Hino T, Saito $\mathrm{H}$, et al. The relationship between chronic hypoxemia and activation of the tumor necrosis factor-alpha system in patients with chronic obstructive pulmonary disease. Am J Respir Crit Care Med. 2000;161(4 Pt 1):1179-84. http:// dx.doi.org/10.1164/ajrccm.161.4.9903022

19. Brucki SM, Nitrini R, Caramelli P, Bertolucci PH, Okamoto IH. Suggestions for utilization of the minimental state examination in Brazil. Arq Neuropsiquiatr. 2003;61(3B):777-81. http://dx.doi.org/10.1590/ S0004-282X2003000500014

20. Camelier A, Rosa FW, Salim C, Nascimento OA, Cardoso F, Jardim JR. Using the Saint George's Respiratory Questionnaire to evaluate quality of life in patients with chronic obstructive pulmonary disease: validating a new version for use in Brazil. J Bras Pneumol. 2006;32(2):11422. http://dx.doi.org/10.1590/S1806-37132006000200006

21. Jones PW, Quirk FH, Baveystock CM. The St George's Respiratory Questionnaire. Respir Med. 
1991;85(Suppl B):25-31. http://dx.doi.org/10.1016/ S0954-6111(06)80166-6

22. De Sousa TC, Jardim JR, Jones P. Validação do Questionário do Hospital Saint George na Doença Respiratória (SGRQ) em pacientes portadores de doença pulmonar obstrutiva crônica no Brasil. J Pneumol. 2000;26(3):119-28. http://dx.doi.org/10.1590/ S0102-35862000000300004

23. Portney LG, Watkins MP. Foundations of clinical research applications to practice. 3rd ed. New Jersey: Pearson Prentice Hall; 2009.

24. De Torres JP, Campo A, Casanova C, Aguirre-Jaime A, Zulueta J. Gender and chronic obstructive pulmonary disease in high-risk smokers. Respiration. 2006;73:306-10. http://dx.doi.org/10.1159/000090051

25. Jaén Díaz JI, De Castro Mesa C, Gontán G, Salamanca MJ, López de Castro F. Prevalence of Chronic Obstructive Pulmonary Disease and Risk Factors in Smokers and ExSmokers. Arch Bronconeumol. 2003;39(12):554-8. http:// dx.doi.org/10.1016/S0300-2896(03)75454-4

26. Pereira CAC. Diretrizes para testes de função pulmonar. J Pneumol. 2002;28:S1-S241.

27. American College Of Sports Medicine. ACSM's Guidelines for Exercise Testing and Prescription. 8th ed. New York: Lippincott Williams \& Wilkins; 2009. chapt. 2, Preparticipation Health Screening and Risk Stratification; p. 18-39.

28. Ries AL, Bauldoff GS, Carlin BW, Casaburi R, Emery $\mathrm{CF}$, Mahler DA, et al. Pulmonary Rehabilitation: Joint ACCP/AACVPR Evidence-Based Clinical Practice Guidelines. Chest. 2007;131(5 Suppl):4S-42S. http:// dx.doi.org/10.1378/chest.06-2418

29. Jones PW, Quirk FH, Baveystock CM, Littlejohns P. A self-complete measure of health status for chronic airflow limitation. The St. George's Respiratory Questionnaire. Am Rev Respir Dis. 1992;145(6):1321-7. http://dx.doi. org/10.1164/ajrccm/145.6.1321

30. Munro BH. Statistical Methods for Health Care Research. 5th ed. Philadelphia: Lippincott Williams \& Wilkins; 2005. chapter 11, Regression; p. 259-86.

31. Pitta F, Troosters T, Probst VS, Langer D, Decramer M, Gosselink R. Are patients with COPD more active after pulmonary rehabilitation? Chest. 2008;134(2):273-80. http://dx.doi.org/10.1378/chest.07-2655

32. Steele BG, Belza B, Cain K, Warms C, Coppersmith J, Howard J. Bodies in motion: Monitoring daily activity and exercise with motion sensors in people with chronic pulmonary disease. J Rehabil Res Dev. 2003;40(5 Suppl. 2):45-58. http://dx.doi.org/10.1682/JRRD.2003.10.0045

33. Skumlien S, Skogedal EA, Bjortuft O, Ryg MS. Four weeks' intensive rehabilitation generates significant health effects in COPD patients. Chron Respir Dis. 2007;4(1):513. http://dx.doi.org/10.1177/1479972306070374

34. Riario-Sforza GG, Incorvaia C, Paterniti F, Pessina L, Caligiuri R, Pravettoni C, et al. Effects of pulmonary rehabilitation on exercise capacity in patients with COPD: a number needed to treat study. Int J Chron Obstruct Pulmon
Dis. 2009;4:315-9. PMid:19750191 PMCid:PMC2740953. http://dx.doi.org/10.1155/2013/374283

35. Garrod R, Marshall J, Barley E, Jones PW. Predictors of success and failure in pulmonary rehabilitation. Eur Respir J. 2006;27(4):788-94. http://dx.doi.org/10.1183/0903193 6.06 .00130605

36. Sewell L, Singh SJ, Williams JE, Collier R, Morgan MD. Can individualized rehabilitation improve functional independence in elderly patients with COPD? Chest. 2005;128(3):1194-200. http://dx.doi.org/10.1378/ chest.128.3.1194

37. Theander K, Jakobsson P, Jorgensen N, Unosson M. Effects of pulmonary rehabilitation on fatigue, functional status and health perceptions in patients with chronic obstructive pulmonary disease: a randomized controlled trial. Clin Rehabil. 2009;23(2):125-36. http://dx.doi. org/10.1177/0269215508096174

38. Pitta F, Takaki MY, Oliveira NH, Sant'Anna TJ, Fontana $\mathrm{AD}$, Kovelis D, et al. Relationship between pulmonary function and physical activity in daily life in patients with COPD. Respir Med. 2008;102(8):1203-7. http://dx.doi. org/10.1016/j.rmed.2008.03.004

39. Huijsmans RJ, De Haan A, The Hacken NNHT, Straver RVM, Van't Hul AJ. The clinical utility of the GOLD classification of COPD disease severity in pulmonary rehabilitation. Respir Med. 2008;102(1):162-71. http:// dx.doi.org/10.1016/j.rmed.2007.07.008

40. Foglio K, Carone M, Pagani M, Bianchi L, Jones PW, Ambrosino N. Physiological and symptom determinants of exercise performance in patients with chronic airway obstruction. Respir Med. 2000;94(3):256-63. http://dx.doi. org/10.1053/rmed.1999.0734

41. Wijkstra PJ, TenVergert EM, Van der Mark TW, Postma DS, Van AR, Kraan J, et al. Relation of lung function, maximal inspiratory pressure, dyspnoea, and quality of life with exercise capacity in patients with chronic obstructive pulmonary disease. Thorax. 1994;49(5):468-72. http:// dx.doi.org/10.1136/thx.49.5.468

42. De Torres JP, Casanova C, Hernandez C, Abreu J, AguirreJaime A, Celli BR. Gender and COPD in patients attending a pulmonary clinic. Chest. 2005;128(4):2012-6. http:// dx.doi.org/10.1378/chest.128.4.2012

43. Ferrari R, Tanni SE, Lucheta PA, Faganello MM, Do Amaral RA, Godoy I. Gender differences in predictors of health status in patients with COPD. J Bras Pneumol. 2010;36(1):37-43. http://dx.doi.org/10.1590/ S1806-37132010000100008

44. Sant'Anna CA, Stelmach R, Zanetti Feltrin MI, Jacob W $\mathrm{F}^{\mathrm{o}}$, Chiba T, Cukier A. Evaluation of health-related quality of life in low-income patients with COPD receiving longterm oxygen therapy. Chest. 2003;123(1):136-41. http:// dx.doi.org/10.1378/chest.123.1.136

45. Tanni SE, Vale SA, Lopes PS, Guiotoko MM, Godoy I, Godoy I. Influence of the oxygen delivery system on the quality of life of patients with chronic hypoxemia. J Bras Pneumol. 2007;33(2):161-7. http://dx.doi.org/10.1590/ S1806-37132007000200010 
46. Dourado VZ, Tanni SE, Antunes LC, Paiva SA, Campana AO, Renno AC, et al. Effect of three exercise programs on patients with chronic obstructive pulmonary disease. Braz J Med Biol Res. 2009;42(3):263-71. http://dx.doi. org/10.1590/S0100-879X2009000300007

47. Mador MJ, Bozkanat E, Aggarwal A, Shaffer M, Kufel TJ. Endurance and strength training in patients with COPD. Chest. 2004;125(6):2036-45. http://dx.doi.org/10.1378/ chest.125.6.2036

48. Takabatake N, Arao T, Sata M, Inoue S, Abe S, Shibata Y, et al. Circulating levels of soluble Fas ligand in cachexic patients with COPD are higher than those in non-cachexic patients with COPD. Intern Med. 2005;44(11):1137-43. http://dx.doi.org/10.2169/internalmedicine.44.1137

49. Stav D, Raz M, Shpirer I. Three years of pulmonary rehabilitation: inhibit the decline in airflow obstruction, improves exercise endurance time, and body-mass index, in chronic obstructive pulmonary disease. BMC Pulm Med. 2009;9:26. http://dx.doi.org/10.1186/1471-2466-9-26

50. Zwick RH, Burghuber OC, Dovjak N, Hartl S, Kossler W, Lichtenschopf A, et al. The effect of one year outpatient pulmonary rehabilitation on patients with COPD. Wien Klin Wochenschr. 2009;121(5-6):189-95. http://dx.doi. org/10.1007/s00508-008-1066-6

51. Geddes EL, Reid WD, Crowe J, O’Brien K, Brooks D. Inspiratory muscle training in adults with chronic obstructive pulmonary disease: a systematic review. Respir Med. 2005;99(11):1440-58. http://dx.doi. org/10.1016/j.rmed.2005.03.006

\section{Correspondence}

\section{Verônica Franco Parreira}

Universidade Federal de Minas Gerais

Physical Therapy Department

Av. Antônio Carlos, 6627

CEP 31270-901, Belo Horizonte, MG, Brazil

e-mail: veronicaparreira@yahoo.com.br;

veronica.parreira@pq.cnpq.br 